\title{
Population Connectivity and
}

\section{Conservation of}

Marine Biodiversity

BY GEOFFREY P. JONES,

MAYA SRINIVASAN, AND

GLENN R. ALMANY

An understanding of the extent to which marine populations are connected by larval dispersal is vital, both to comprehend past impacts and future prospects for sustaining biodiversity. Marine populations and their supporting ecosystems are now subject to a multitude of threats, most notably overharvesting, pollution, and climate change (Hixon et al., 2001; Jackson et al., 2001; Hutchings and Reynolds, 2004; Kappel, 2005; Lotze et al., 2006). The intensity and scale of anthropogenic impacts in the world's ocean have increased dramatically during the industrial age (Jackson et al., 2001; Lotze et al., 2006), and these impacts are combining to accelerate the loss and fragmentation of important coastal marine habitats, including mangroves (Ellison and Farnsworth, 1996; Alongi, 2002), seagrasses (Duarte, 2002; Orth et al., 2006), kelp forests (Dayton et al., 1998; Steneck et al., 2002), and coral reefs (McClanahan, 2002; Gardiner et al., 2003; Hughes, et al., 2003; Aronson and Precht, 2006). The increasing risk of extinction in the sea is widely acknowledged (Roberts and Hawkins, 1999; Powles et al., 2000; Dulvy et al., 2003; Kappel, 2005; Reynolds et al., 2005), and the conservation of marine biodiversity has become a high priority for researchers and managers alike. 
The increasing diversity, intensity, and scale of human impacts on marine systems will likely reduce potential connectivity among remnant populations, due to declining numbers and increasing fragmentation. It follows that the resilience of a species to these impacts will depend to a large degree on its dispersal capability. Marine larvae exhibit extremes of larval dispersal, from those that travel just a few meters to others with the potential to disperse thousands of kilometers (Kinlan and Gaines, 2003; Shanks et al., 2003). Species with wide dispersal capabilities may be less susceptible to global extinction because of their large ranges, multiple populations, and potential for local recovery through larval transport. On the other hand, invasive species and disease vectors with high dispersal potential pose greater global threats to marine biodiversity. The problem we face is that the actual larval dispersal distances of highly overfished, threatened, or invasive species are seldom known. While new technologies are leading to major discoveries concerning the scales of dispersal (Thorrold et al., 2002; Palumbi et al., 2003; Levin, 2006), as yet, this knowledge is too incomplete to be comprehensively incorporated into management strategies (Sale et al., 2005).

Most approaches to the management of marine species and ecosystems are based on untested assumptions about typical larval dispersal distances. Understanding connectivity is critical both for the design of marine reserve networks to protect biodiversity and for the development of conservation strategies to protect species associated with degrading and fragmenting seascapes. The aims of this essay are to highlight recent advances in our understanding of larval retention and connectivity, and to explore their implications for evaluating threats to marine biodiversity as well as different management options for minimizing these threats.

\section{MARINE RESERVES AND}

\section{BIODIVERSITY PROTECTION}

Marine reserves or no-take marine protected areas (MPAs) are now routinely established both as fisheries management tools and for biodiversity protection.

However, while there is ample evidence that MPAs can provide a host of benefits to exploited populations within their boundaries (Roberts and Polunin, 1991; Jones et al., 1993; Halpern and Warner, 2002; Halpern, 2003), the effectiveness of MPA networks in biodiversity protection has received much less attention. Ideally, marine reserves should encompass representative regions/habitats so as to protect as much of the regional biodiversity be of limited benefit where habitat loss and fragmentation, pollution, and climate change are contributing to declines in marine biodiversity (Allison et al., 1998; Jameson et al., 2002; Jones et al., 2004; Aronson and Precht, 2006). Also, if MPAs simply result in a displacement of fishing effort (Hilborn et al., 2004, 2006), potential benefits of biodiversity protection inside MPAs may be offset by an increase in the detrimental effects of fishing outside reserves.

In some situations, the design of MPA networks for fisheries management and biodiversity protection may have conflicting goals or outcomes. The optimal sizes of MPAs for biodiversity conservation are likely to be larger than those designed for protecting fish stocks and enhancing recruitment to adjacent fished areas (Hastings and Botsford, 2003). Large MPAs may be ideal for biodiversity conservation because they encompass more species, but they may limit the

\section{...a much greater knowledge of connectivity is required in order to optimize strategies for conserving marine biodiversity.}

as possible (e.g., Airame et al., 2003;

Beger et al., 2003; Fernandes et al., 2005). However, the degree to which reserves achieve the goal of "protecting" species is uncertain. Given that the majority of marine species are not eaten (at least not yet), closing areas to fishing or collecting does not necessarily address the primary threats to most species. MPAs may exploitation of fish stocks to well below sustainable levels. Small MPAs may provide a protective umbrella for the biodiversity of sedentary species but are unlikely to provide an effective refuge for highly mobile exploited species (Hilborn et al., 2004; Nardi et al., 2004). Increases in the abundance and biomass of large exploited predators or space occupiers 
in reserves may result in the decline of prey or inferior competitors, and thus an overall decline in biodiversity (Jones et al., 1993; Micheli et al., 2004). Getting the right balance between reserve design for both exploitation and conservation requires a detailed understanding of larval dispersal patterns for the widest possible range of marine species.

\section{NEW DISCOVERIES ON VARIATION IN DISPERSAL: IMPLICATIONS FOR MANAGEMENT}

Directly tracking the movements of marine organisms through their pelagic larval stages is seldom possible. However, recent advances in technology are providing new insights into the extent of marine larval dispersal, indicating more local retention and a greater variation in dispersal distances than once appreciated. Direct larval marking (Jones et al., 1999, 2005; Almany et al., 2007), advanced genetic techniques (Jones et al., 2005; Purcell et al., 2006; Gerlach et al., 2007), biophysical and hydrodynamic models (Cowen et al., 2000, 2006; James et al., 2002), metapopulation models (Armsworth, 2002; Hastings and Botsford, 2006), and fish otolith chemistry (Swearer et al., 1999) have all indicated both significant local retention and the potential for long-distance dispersal.

Many larvae may settle much closer to home than once thought possible. For example, larval marking studies at two small islands in Kimbe Bay, Papua New Guinea, (Figure 1a) show that a large proportion of juveniles of three fish species are locally spawned. Jones et al. (2005) used both direct larval marking (embryo immersion in tetracycline) and genetic parentage analysis to examine retention of clownfish (Amphiprion polymnus) larvae at Schumann Island. They showed that a significant proportion $(\sim 30 \%)$ of larvae settling at the island were within a few hundred meters of their parents, despite a pelagic larval duration (PLD) of 10 days (Figure $1 \mathrm{~b}$ ). Almany et al. (2007) marked larvae of another clownfish (A. percula) with an 11-day PLD and a butterflyfish (Chaetodon vagabundus) with a 38-day PLD at Kimbe Island using maternally transmitted barium isotopes (Figure 1c). They found that $60 \%$ of the juveniles of both species were locally spawned, returning to a reef of only $0.3 \mathrm{~km}^{2}$. In both studies, the other immigrant juveniles must have traveled $10-20 \mathrm{~km}$ from

GEOFFREY P. JONES (geoffrey.jones@jcu. edu.au) is Professor, School of Marine and Tropical Biology, and Chief Investigator, Australian Research Council Centre of Excellence for Coral Reef Studies, James Cook University, Townsville, Queensland, Australia. MAYA SRINIVASAN and GLENN R. ALMANY are Postdoctoral Researchers, Australian Research Council Centre of Excellence for Coral Reef Studies, James Cook University, Townsville, Queensland, Australia.
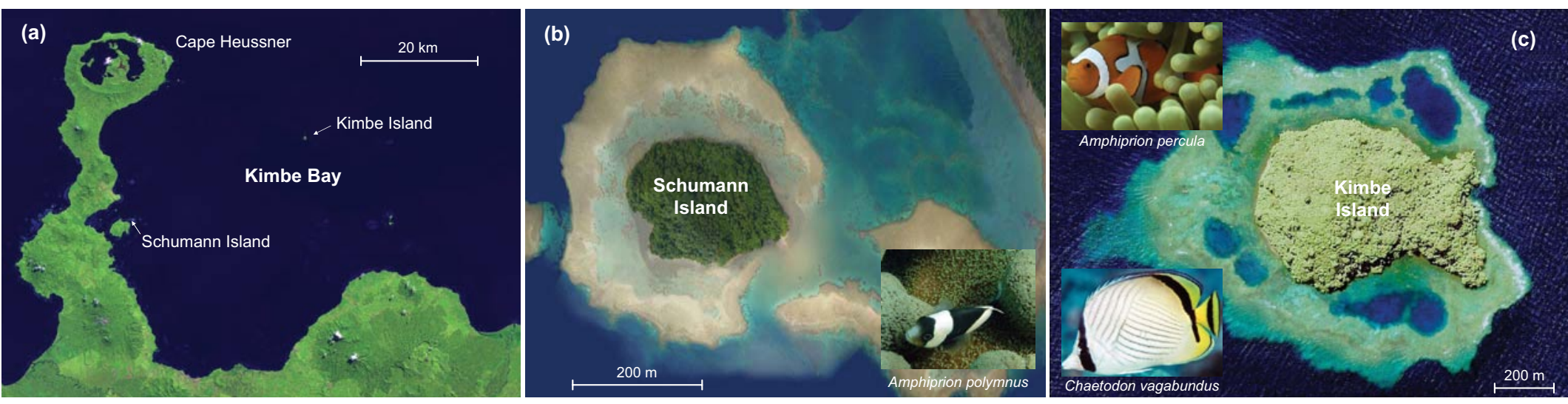

Figure 1. (a) Kimbe Bay, Papua New Guinea. Direct larval marking studies at two islands (Schumann and Kimbe) show that many coral reef fish larvae settle much closer to home than previously thought. (b) Schumann Island. Larval marking via tetracycline immersion of embryos and genetic parentage analysis demonstrated $\sim 30 \%$ self-recruitment in a population of the panda clownfish (Amphiprion polymnus), which have a 10-day pelagic larval duration. (c) Kimbe Island. Larval marking via maternal transmission of stable barium isotopes demonstrated $~ 60 \%$ self-recruitment in both the orange clownfish (A. percula; 11 -day pelagic larval duration) and the vagabond butterflyfish (Chaetodon vaganbundus; 38-day pelagic larval duration). Percent of self-recruitment was defined as the proportion of the recruitment to a population that was a product of that population. 
the nearest adjacent populations. Hence, reef fishes from semi-isolated subpopulations with a range of PLDs can exhibit a wide variance and multimodal patterns in dispersal distances.

Realized dispersal distances may be explained by a combination of the actual dispersal potential (a dispersal kernel based on how far larvae have the intrinsic ability to disperse) and the distribution of suitable habitat (Figure 2). Where suitable habitat is continuous and not saturated, the observed connectivity through much of the range may relate closely to larval dispersal potential (Figure $2 \mathrm{a}-\mathrm{c}$ ). The higher the variance in dispersal, the greater the realized connectivity within a species' population range (Figure 2c). More often than not, suitable habitat is discontinuous, and marine (meta) populations are made up of many subpopulations that are linked to an unknown degree and distance by larval dispersal (Figure 2d-f) (Kritzer and Sale, 2004). Greater dispersal abilities do not necessarily increase realized dispersal unless they are sufficient to bridge the gaps between isolated patches of suitable habitat (Figure 2d,e). A wide variance in dispersal kernels, including significant levels of self-recruitment, will result in multimodal patterns of realized dispersal that will maximize the persistence of the metapopulation (Figure 1f) (Hastings and Botsford, 2006).

Realized dispersal patterns have important strategy implications for biodiversity conservation, such as optimal reserve size and spacing. As a general rule, an increasing range of effective dispersal will require larger MPAs to achieve recruitment benefits within

\section{CONTINUOUS HABITAT}

(a) Low

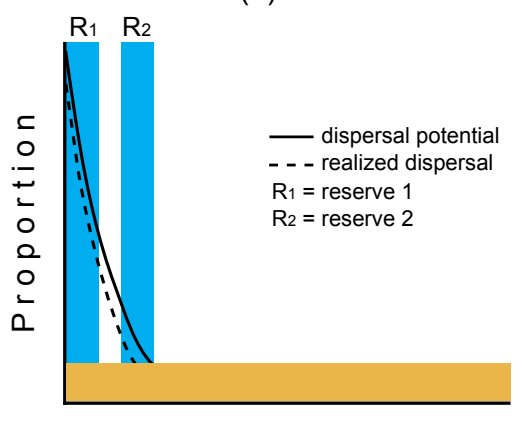

(b) Medium

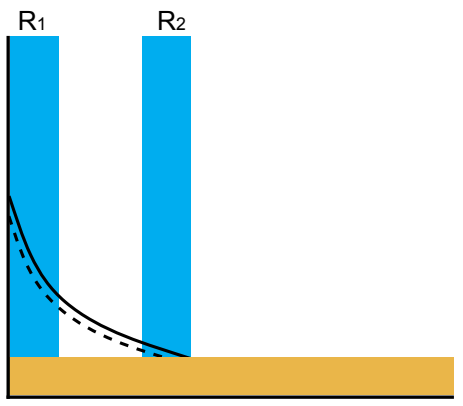

FRAGMENTED HABITAT

(d) Low

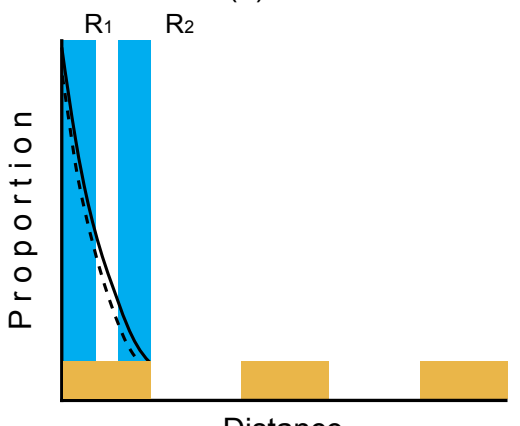

(e) Medium

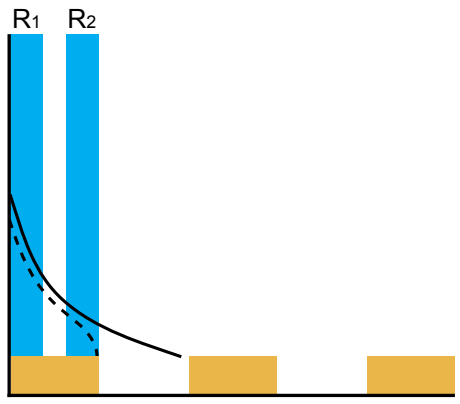

Distance (c) High

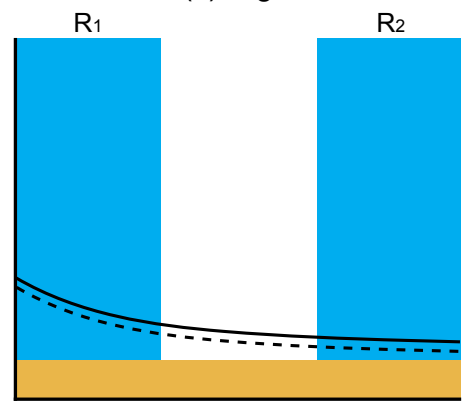

(f) High

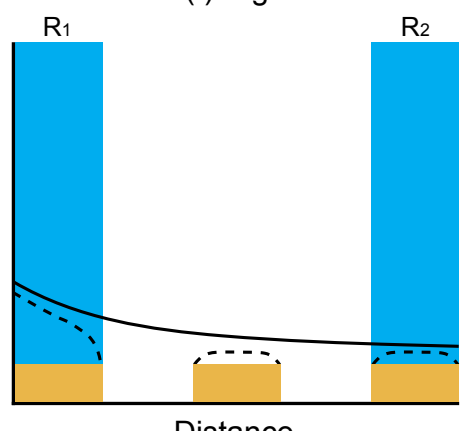

Figure 2. Schematic representation of the influence of dispersal potential and habitat fragmentation on realized dispersal and optimal reserve size and spacing. Where habitat (orange horizontal bars) is continuous, realized dispersal reflects dispersal potential, and optimal reserve (blue vertical bars) size and spacing increase with variance in realized dispersal $(\mathrm{a}-\mathrm{c})$. Where habitat is discontinuous, realized dispersal reflects a combination of dispersal potential and habitat fragment size and spacing (d-f). Realized dispersal only occurs if dispersal potential is sufficient to bridge gaps between patches of habitat. Optimal reserve size and spacing will be constrained by the size and spacing of habitat fragments. 
boundaries and will allow a greater spacing of MPAs to achieve recruitment benefits beyond boundaries or connectivity among MPAs (Figure 2a-c). Where habitat is discontinuous, the optimal reserve representation of species inside reserves (e.g., Diamond, 1975; Simberloff, 1988; Margules et al., 1982; Pressey et al., 1993). These approaches are increasingly being applied to MPA design, particu-

\section{Critical questions, such as how population}

connectivity will be influenced by the increasing loss and fragmentation of marine
habitats, are only beginning to be answered.

size and spacing to ensure retention and connectivity may be constrained by the size and spacing of habitat patches. Subpopulations that are not connected because of limited dispersal capability, geographic isolation, or increasing habitat fragmentation (Figure 1d,e), will take high conservation priority because of their reduced ability to recover from local depletion or habitat degradation (Roberts et al., 2006).

\section{CONNECTIVITY AND THE}

\section{DESIGN OF MARINE RESERVE}

\section{NETWORKS TO PROTECT}

\section{BIODIVERSITY}

The design of MPA networks, including the size of individual reserves, the number of reserves, cumulative total reserve area, the trade-off between a few large or several small reserves, and the spacing and locations of reserves, can be varied to achieve different conservation goals. Most recommendations for the design of MPA networks are based on theory and practices that maximize the larly in relation to site selection (Turpie et al., 2000; Roberts et al., 2002, 2003; Beger et al., 2003; Fox and Beckley, 2005; Fernandes et al., 2005).

There are relatively few analyses that explicitly incorporate larval connectivity and population persistence in reserve design, and those that do primarily focus on reserves for fisheries management (Roberts, 1997; Botsford et al., 2001; Lockwood et al., 2002; but see Hastings and Botsford, 2003). These models set out to predict the optimal size, spacing, or cumulative area under different levels of dispersal. However, until realized dispersal distances are confirmed for a wide variety of species, application of these models is limited. Typical larval dispersal distances, often inferred from indirect information such as PLD or measures of genetic distance, have been used to argue for the optimal size and spacing of marine reserves for particular marine taxa (e.g., Sala et al., 2002; Shanks et al., 2003; Palumbi, 2004; Mora et al., 2006). However, "typical” dis- persal distances may under-represent the potential spread of larvae from source populations.

If we explicitly incorporate larval retention and connectivity into the design of MPA networks for biodiversity conservation, then optimal outcomes depend on whether the goal is to maximize benefits within MPAs, beyond their boundaries, or a balance between these objectives (Figure 3). Individual, isolated MPAs cannot function as sanctuaries for threatened species within their boundaries unless the populations are big enough and there is sufficient self-recruitment to ensure persistence. Also, they cannot function as sources to repopulate locally extinct populations beyond their boundaries unless there is sufficient longerdistance dispersal to do so. Given the likely variance in dispersal (based on the information gathered so far), it is highly probable that reserve size and spacing can be adjusted to achieve both of these goals (Halpern and Warner, 2002; Jones et al., 2005; Almany et al., 2007).

\section{Reserve Size: Large Versus Small}

The pros and cons of small versus large marine reserves have received increased attention (Halpern, 2003; Roberts et al., 2003; Palumbi, 2004; Sale et al., 2005). There is substantial variation in the size of existing no-take MPAs, from $<1 \mathrm{~km}^{2}$ to $>1000 \mathrm{~km}^{2}$ (Halpern 2003), but which is best? Even the smallest reserves monitored appear to have local benefits in terms of increases in fished species (e.g., Roberts and Hawkins, 1997; Francour et al., 2001). However, in MPA networks, larger reserves have advantages in terms of protecting significantly larger populations (Halpern, 2003) and 
enforcing compliance (Kritzer, 2004;

Little et al., 2005).

In terms of connectivity, extremely small reserves will provide minimal

(a) Reserve size

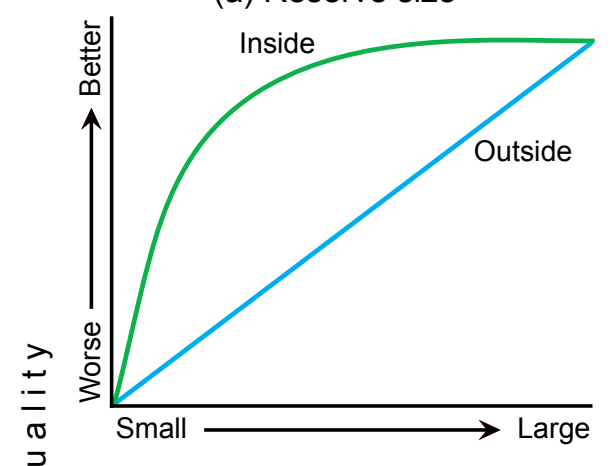

(c) Total reserve area

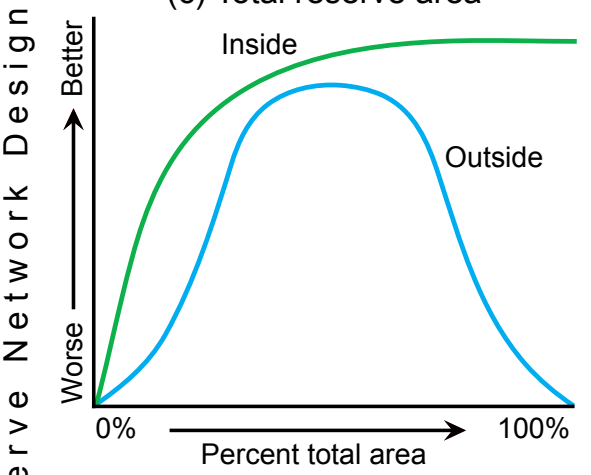

(e) Reserve spacing

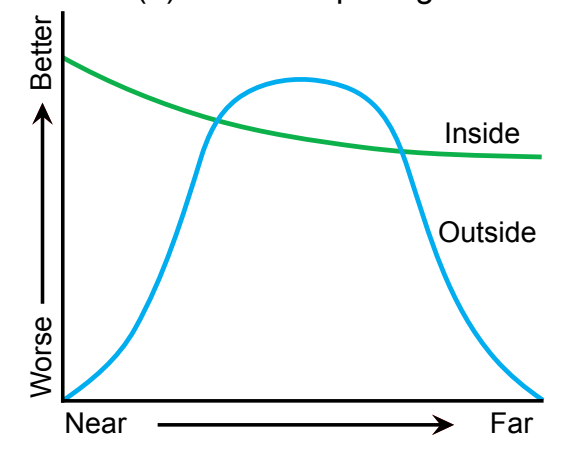

Reserve recruitment benefits either inside or beyond their boundaries (Figure 3a). With significant local self-recruitment, the benefit inside reserves should rise

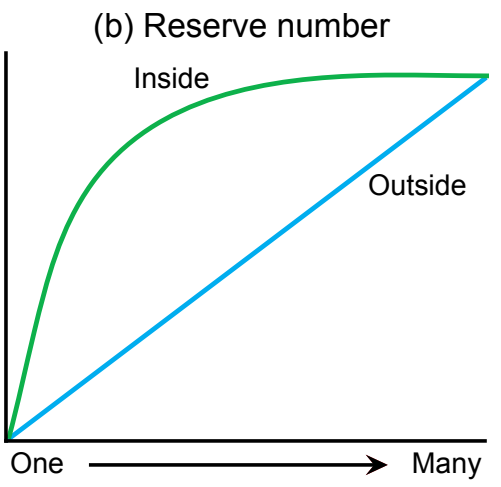

(d) Single large or several small

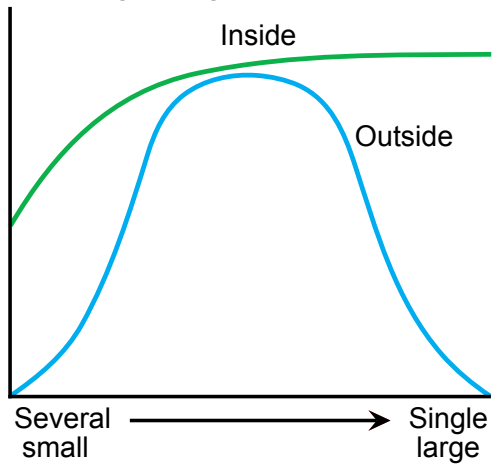

(f) Reserve location

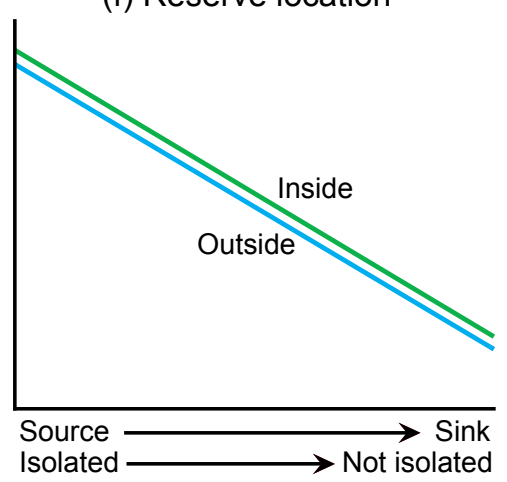

Parameter

Figure 3. Design guidelines for marine protected area networks based on connectivity and achieving optimal outcomes for recruitment benefits inside (green line) and outside (blue line) boundaries. (a) Individual reserve size. (b) Number of reserves. (c) Total reserve area (as percentage of total habitat). (d) Single large versus several small. (e) Reserve spacing. (f) Reserve location (source versus sink, isolated versus clustered). These guidelines are based on an assumption of a wide variance in dispersal ranges, including a significant level of localized recruitment.

dramatically with reserve size. However, little benefit may be achieved by increasing reserve size above the level at which persistent populations can be achieved. Lockwood et al. (2002) calculated that to have a persistent population in an isolated reserve, reserve size should be about two times the mean dispersal distance to ensure that it is substantially self-recruiting. Recruitment subsidies beyond boundaries will increase in proportion to the perimeter of the reserve, so a bigger reserve will always be better.

Few have attempted to put actual dimensions on optimal reserve size based on mean larval dispersal estimates. Shanks et al. (2003) argue that marine reserves should be $4-6 \mathrm{~km}$ in diameter to be large enough to contain the larvae of short-distance dispersers. However, Palumbi (2004) argues that greater variation in reserve sizes $(1-100 \mathrm{~km}$ in diameter) is necessary due to the large variance in dispersal distances across taxa. Laurel and Bradbury (2006) suggest larval dispersal distances in fishes increase substantially with latitude, suggesting marine reserves in temperate climes should be larger than those in the tropics.

\section{Reserve Number}

Assuming reserve sizes are the same, for conservation purposes, it should also be better to have as many MPAs as possible (Figure 3b). However, self-sustaining populations inside reserves may be achieved by a relatively small number of reserves, while recruitment subsidies outside reserves and connectivity among reserves should increase in proportion to reserve number (Figure 3b) (Roberts et al., 2006). 


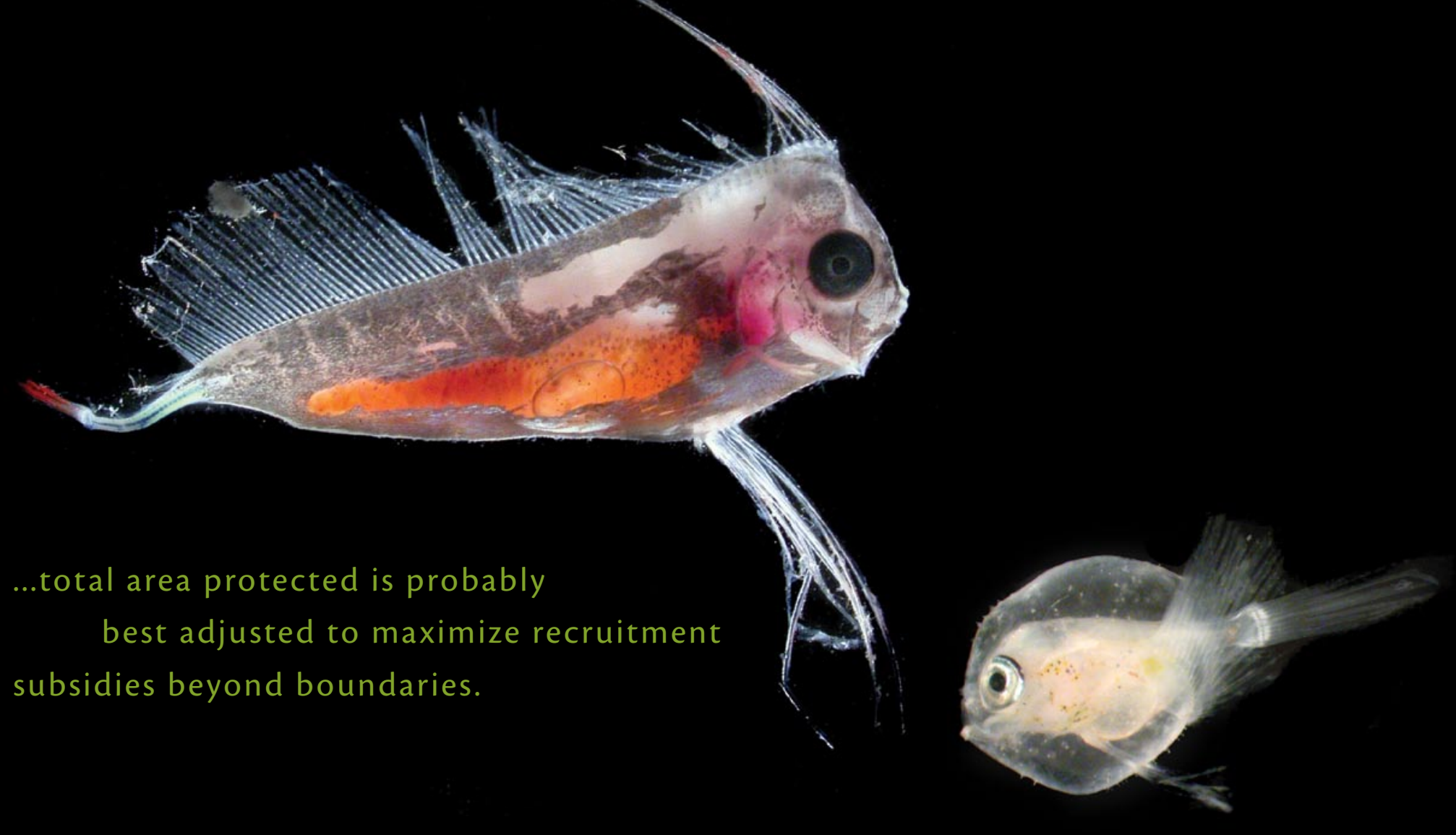

\section{Total Reserve Area}

The conservation benefits of MPAs inside and outside reserves vary in relation to the proportion of the total area to be protected (Hastings and Botsford, 2003). At the lower extreme, with $0 \%$ of the habitat inside MPAs, obviously there can be no benefits either within or beyond boundaries. However, if $100 \%$ of the available habitat were protected, this would maximize the benefits within boundaries but provide no benefits beyond boundaries (Figure 3c). While this could be seen as a fundamental conflict between designing MPAs for biodiversity protection and for sustainable fishing, increasing evidence for localized recruitment suggests that a relatively small total area will support self-sustaining populations. While inter-reserve connectivity will increase with the total proportion protected (Roberts et al., 2006), such high levels of exchange may be unnecessary for persistence inside reserves. Hence, total area protected is probably best adjusted to maximize recruitment subsidies beyond boundaries.

Few workers have put a figure on the proportion of the total habitat area inside reserves that is required for biodiversity conservation, although recommendations ranging between 20 and 50\% have been published (e.g., Botsford et al., 2001, > 35\%; Sala et al., 2002, 40\%; Airame et al., 2003, 30-50\%; Gell and Roberts, 2003, 10-20\%; Halpern et al., 2004, < 50\%). Theoretically, the total area needed will increase with decreasing connectivity (Roberts et al., 2006). Small, unique habitats or endangered species will require protection of $100 \%$ of the habitat or the area supporting the population.
4. Single Large or Several Small:

\section{The SLOSS Debate}

The decision over whether a fixed proportion of the total reserve area should be divided into either a few large or many small reserves is an important practical decision faced by managers. There has been conflicting opinion over which strategy maximizes the number of species inside reserves, the so-called SLOSS debate (Single Large or Several Small) (Diamond, 1975; Simberloff, 1988). Whether or not one of these alternatives is better than the other depends on the degree to which small reserves represent nested subsamples of species from larger reserves (Lomolino, 1994; Worthen, 1996). The few published comparisons of small and large marine reserves suggest that it may not make much difference to the number of species protected (McNeill and Fairweather, 
1993; Stockhausen and Lipcius, 2001).

In terms of larval dispersal and biodiversity protection, whether a single large or several small is better again depends on the goal. A single large MPA may maximize population persistence through self-recruitment, but several smaller MPAs will maximize recruitment beyond boundaries (Hastings and Botsford, 2003) (Figure 3d). However, if there is a high level of local retention, it is unlikely that it would make any difference over a broad range of reserve size/ number combinations. Several mediumsized reserves, appropriately spaced, are likely to maximize recruitment subsidies from MPAs, simply because the magnitude of recruitment subsidies should increase as a function of the sum of the circumferences of all reserves (Figure 3d).

\section{Reserve Spacing}

As long as individual reserves are sufficiently large to be substantially selfsustaining, the spacing of reserves may have little effect on reserve population persistence (Figure 3e). Persistence of populations inside reserves may be marginally better if reserves are close together, because of increased recruitment subsidies from other reserves (Roberts et al., 2006). However, spacing will be much more critical to maximizing recruitment subsidies outside reserves. Again, there is likely to be an optimal spacing, because if they are too close, this effectively restricts the area in between, and if they are too far apart, they will not receive recruits from other reserves. As a general rule, the lower the effective dispersal, the closer MPAs will have to be to provide benefits to unprotected areas (see Figure 2a-c).
There are a few specific recommendations about MPA spacing based on generalizations about dispersal distances. Shanks et al. (2003) recommend a spacing of 10-20 km for species with typical pelagic larval durations to promote connectivity among adjacent reserves. However, Palumbi (2004) argues for more variation in spacing $(10-200 \mathrm{~km})$ to reflect the likely variation in the dispersal abilities of fish and invertebrates. Kaplan and Botsford (2005) show that variable spacing is better than fixed spacing when there are several small reserves rather than few large reserves.

\section{Reserve Location}

Discussions about reserve location in relation to connectivity center on three main issues: (1) protecting source populations, (2) protecting isolated populations, and (3) protecting spawning aggregation sites. Larval "sources," if they can be identified, make better reserves outside reserves. Sinks (places that rely solely on larvae imported from upstream for their persistence) will receive little benefit from protection and should be resilient to "recruitment" overfishing (Roberts, 1997).

It has been suggested further that potential source reefs that are resistant to perturbations should have the highest MPA value, as they alone can source the recovery of damaged habitats (Salm et al., 2006). However, while protecting source populations is critical, locating them is a difficult matter. Populations are usually classified as sources on the basis of hydrodynamic models (Roberts, 1997; Bode et al., 2006). For example, Bode et al. (2006) predicted that populations on the northern Great Barrier Reef in Australia are self-sustaining source reefs, while those in the south may be reliant on the north for their persistence. However, models that incorporate larval behavior and demography suggest that

\section{...the increasing evidence for local retention of larvae argues that biophysical models must be able to predict patterns of dispersal and connectivity at fine spatial scales.}

than "sink" populations (Roberts, 1997), regardless of whether the priority is biodiversity conservation or fisheries management. Sources must be prioritized because they (a) must be self-recruiting to persist, and (b) will provide an aboveaverage recruitment subsidy to areas the scale at which marine populations act as sources may be more limited than once thought (Cowen et al., 2006).

Isolated islands or habitats have a high conservation priority because they often have unique assemblages and populations that are disconnected from all 
others (Jones et al., 2002; Roberts et al., 2006; Perez-Ruzafa et al., 2006). Sources of replenishment for populations along coastlines or archipelagos may be greater, affording them greater resilience. Given that isolated islands rely on self-recruitment for their persistence, protecting a relatively high proportion of the reproductive population may be necessary to avoid potential extinction.

Many large marine organisms gather at widely separated, but spatially predictable, spawning aggregation or breeding sites (Vincent and Sadovy, 1998; Claydon, 2005). As these areas encompass the main sources of larvae for local or regional replenishment of populations, their protection is of paramount importance (Roberts et al., 2006).

However, where and how far larvae go from particular aggregation sites remains a mystery. On coral reefs, populations returning to well-known aggregation sites are generally in decline, and recov-
WHY MARINE RESERVES ARE INSUFFICIENT TO CONSERVE MARINE BIODIVERSITY

It is increasingly appreciated that marine reserves "are necessary, but not sufficient" to manage exploited species or protect marine biodiversity (Allison et al., 1998; Jameson et al., 2002; Aronson and Precht, 2006). A comprehensive management plan must involve minimizing human impacts both inside and outside MPAs. Individual populations and local biodiversity inside MPAs can be threatened by the buildup of large predators (Jones et al., 1993; Micheli et al., 2004) and extrinsic sources of environmental degradation, such as sedimentation and global climate change (Allison et al., 1998; Rogers and Beets, 2001; Jones et al., 2004). Although some exploited populations in degraded MPAs can benefit from protection (Hawkins et al., 2006), the majority of unexploited species may not. An idealized MPA

\section{The increasing risk of extinction in the sea is widely acknowledged..., and the conservation of marine biodiversity has become a high priority for researchers and managers alike.}

ery at locally extinct aggregation sites is limited (Sadovy, 1993; Sala et al., 2001). Local management of individual spawning aggregation sites may be critical if particular sites are not replenished from other sources. network based on reliable estimates of dispersal may change if ocean warming and climatic conditions alter patterns of circulation and larval development (Munday et al., 2007). MPA networks cannot be designed to encompass all rare and potentially threatened species within their boundaries without restricting access to an unreasonably large total reserve area. Hence, such species will always require a safety net of management actions outside MPAs (Jones et al., 2002). Overfished species may also need to be managed outside protected areas, both to control overall fishing effort (Hilborn et al., 2004, 2006) and to ensure an adequate source of larvae for all unprotected areas (Almany et al., 2007).

\section{CONCLUSIONS}

Clearly, a much greater knowledge of connectivity is required in order to optimize strategies for conserving marine biodiversity. To our knowledge, empirical estimates of connectivity have never been incorporated into the design and implementation of an MPA network. While improved estimates of connectivity may not bring about changes to existing MPA networks, it will help us to understand how they operate and to identify any deficiencies. Hopefully, future MPA designs will explicitly take into account larval sources, optimal MPA sizes for animal sanctuaries, and optimal spacing to maximize recruitment subsidies in non-MPA areas. While there is increasing direct evidence that MPAs can provide benefits within and beyond their boundaries, such evidence is limited. There is also information to suggest that extrinsic disturbances from beyond their boundaries can negate these benefits. Critical questions, such as how population connectivity will be influenced by the increasing loss and fragmentation of marine habitats, are only beginning to be answered.

It is impractical to suggest that we will ever have detailed empirical data on 
larval dispersal for all marine species. Ultimately, we must rely on biophysical models or other proxies of dispersal that can be applied across a range of species with similar life history characteristics. However, the increasing evidence for local retention of larvae argues that biophysical models must be able to predict patterns of dispersal and connectivity at fine spatial scales. Cross-validation of different techniques for estimating dispersal and testing predictions using larval marking studies will be necessary to increase the reliability of these models.

To a large extent, managing marine biodiversity on the basis of information on connectivity will be a balancing act, exploiting the advantages and minimizing the disadvantages of the extremes of dispersal. For species or habitats with low connectivity, local protection of populations will be enhanced, small reserves will be effective, and there will be demonstrable benefits for local fisheries and less need for international cooperation in management. Low-dispersal regions may also be more impervious to invasive species and pests. However, with low connectivity comes the greater threat of local and global extinction, and low recruitment subsidies from MPAs or refuge populations. The total reserve area may have to be large and reserves closely spaced to maximize their benefits.

On the other hand, with high larval dispersal and connectivity, subpopulations will be resilient to local extinctions and recruitment subsidies from MPAs, and remnant populations will be greater. However, total protection of a population or species may be impossible, the value of small reserves may be limited, and there will be a premium on inter- national cooperation, especially among small countries.

The large range in dispersal distances that has been observed, even within species, is probably no accident. Populations that are capable of persisting through either mechanisms of self-recruitment or from larval supply from upstream populations will be resilient to the widest range of disturbances. This variance may be sufficient to ensure populations can benefit from a wide range of MPA sizes and configurations, and indeed that may be the best strategy. While it is unlikely that we can hope to get the management of all marine species completely right, we can take comfort in the fact that it would also be impossible to get it completely wrong.

\section{ACKNOWLEDGEMENTS}

This manuscript has benefited from discussions with members of the ARC Centre of Excellence for Coral Reef Studies Connectivity Program, and members of the Coral Reef Targeted Research and Capacity Building (CRTR) Program, Connectivity Working Group (CWG). Special thanks to S. Thorrold and an anonymous reviewer for their contributions to the final draft. 还

\section{REFERENCES}

Airame, S., J.E. Dugan, K.D. Lafferty, H. Leslie, D.A. McArdle, and R.R. Warner. 2003. Applying ecological criteria to marine reserve design: A case study from the California Channel Islands. Ecological Applications 13:S170-S184.

Allison, G.W., J. Lubchenco, and M.H. Carr. 1998. Marine reserves are necessary but not sufficient for marine conservation. Ecological Applications 8:S79-S92.

Almany, G.R., M.L. Berumen, S.R. Thorrold, S. Planes, and G.P. Jones. 2007. Local replenishment of coral reef fish populations in a marine reserve. Science 316:742-744.

Alongi, D.M. 2002. Present state and future of the world's mangrove forests. Environmental Conservation 29:331-349.

Armsworth, P.R. 2002. Recruitment limitation, population regulation, and larval connectivity in reef fish metapopulations. Ecology 83:1,092-1,104.

Aronson, R.B., and W.F. Precht. 2006. Conservation, precaution, and Caribbean reefs. Coral Reefs 25:441-450.

Beger, M., G.P. Jones, and P.L. Munday. 2003. Conservation of coral reef biodiversity: A comparison of reserve selection procedures for corals and fishes. Biological Conservation 111:53-62.

Bode, M., L. Bode, and P.R. Armsworth. 2006. Larval dispersal reveals regional sources and sinks in the Great Barrier Reef. Marine Ecology Progress Series 308:17-25.

Botsford, L.W., A. Hastings, and S.D. Gaines. 2001. Dependence of sustainability on the configuration of marine reserves and larval dispersal distance. Ecology Letters 4:144-150.

Claydon, J. 2005. Spawning aggregations of coral reef fishes: Characteristics, hypotheses, threats and management. Oceanography and Marine Biology: An Annual Review 42:265-301.

Cowen, R.K., K.M.M. Lwiza, S. Sponaugle, C.B. Paris, and D.B Olson. 2000. Connectivity of marine populations: Open or closed? Science 287:857-859.

Cowen, R.K., C.B. Paris, and A. Srinivasan. 2006. Scaling of connectivity in marine populations. Science 311:522-527.

Dayton, P.K., M.J. Tegner, P.B. Edwards, and K.L. Riser. 1998. Sliding baselines, ghosts, and reduced expectations in kelp forest communities. Ecological Applications 8:309-322.

Diamond, J.M. 1975. The island dilemma: Lessons of modern biogeographic studies for the design of nature reserves. Biological Conservation 7:129-146.

Duarte, C.M. 2002. The future of seagrass meadows. Environmental Conservation 29:192-206.

Dulvy N.K., Y. Sadovy, and J.D. Reynolds. 2003. Extinction vulnerability in marine populations. Fish and Fisheries 4:25-64.

Ellison, A.M., and E.J. Farnsworth. 2006. Anthropogenic disturbance of Caribbean mangrove ecosystems: Past impacts, present trends, and future predictions. Biotropica 28:549-565.

Fernandes, L., J. Day, A. Lewis, S. Slegers, B. Kerrigan, D. Breen, D. Cameron, B. Jago, J. Hall, D. Lowe, and others. 2005. Establishing representative no-take areas in the Great Barrier Reef: Large-scale implementation of theory on marine protected areas. Conservation Biology 19:1,733-1,744.

Fox, N.J., and L.E. Beckley. 2005. Priority areas for conservation of Western Australian coastal fishes: A comparison of hotspot, biogeographical and complementarity approaches. Biological Conservation 125:399-410.

Francour, P., J.G. Harmelin, D. Pollard, and S. Sartoretto. 2001. A review of marine protected areas in the northwestern Mediterranean region: Siting, usage, zonation and management. Aquatic 
Conservation: Marine and Freshwater Ecosystems 11:155-188.

Gardiner, T.A., I.M. Cote, J.A. Gill, A. Grant, and A.R. Watkinson. 2003. Long-term region-wide declines in Caribbean corals. Science 301:958-960.

Gell, F.R., and C.M. Roberts. 2003. Benefits beyond boundaries: The fishery effects of marine reserves. Trends in Ecology and Evolution 18:448-455.

Gerlach, G., J. Atema, M.J. Kingsford, K.P. Black, and V. Miller-Sims. 2007. Smelling home can prevent dispersal of reef fish larvae. Proceedings of the National Academy of Sciences of the United States of America 104:858-863.

Halpern, B.S. 2003. The impact of marine reserves: Do reserves work and does reserve size matter? Ecological Applications 13:S117-S137.

Halpern, B.S., S.D. Gaines, and R.R. Warner. 2004. Confounding effects of the export of production and the displacement of fishing effort from marine reserves. Ecological Applications 14:1,248-1,256.

Halpern, B.S., and R.R. Warner. 2002. Marine reserves have rapid and lasting effects Ecology Letters 5:361-366.

Hastings, A., and L.W. Botsford. 2003. Comparing designs of marine reserves for fisheries and for biodiversity. Ecological Applications 13:S65-S70.

Hastings, A., and L.W. Botsford. 2006. Persistence of spatial populations depends on returning home. Proceedings of the National Academy of Sciences of the United States of America 103:6,067-6,072.

Hawkins, J.P., C.M. Roberts, C. Dytham, C. Schelten, and M.M. Nugues. 2006. Effects of habitat characteristics and sedimentation on performance of marine reserves in St. Lucia. Biological Conservation 127:487-499.

Hilborn. R., F. Micheli, and G.A. De Leo. 2006. Integrating marine protected areas with catch regulation. Canadian Journal of Fisheries and Aquatic Sciences 63:642-649.

Hilborn, R., K. Stokes, J.J. Maguire, T. Smith, L.W. Botsford, M. Mangel, J. Orensanz, A. Parma, J. Rice, J. Bell, and others. 2004. When can marine reserves improve fisheries management? Ocean \& Coastal Management 47:197-205.

Hixon, M.A., P.D. Boersma, M.L. Hunter Jr., F. Micheli, E.A. Norse, H.P. Possingham, and P.V.R. Snelgrove. 2001. Oceans at risk. Pp. 125-154 in Conservation Biology: Research Priorities for the Next Decade. M. Soulé and G. Orians eds, Island Press, Washington, DC

Hughes, T.P., A.H. Baird, D.R. Bellwood, M. Card, S.R. Connolly, C. Folke, R. Grosberg, O. HoeghGuldberg, J.B.C. Jackson, J. Kleypas, and others. 2003. Climate change, human impacts and the resilience of coral reefs. Science 301:929-933.

Hutchings, J.A., and J.D. Reynolds. 2004. Marine fish population collapses: Consequences for recovery and extinction risk. Bioscience 54:297-309.

Jackson, J.B.C., M.X. Kirby, W.H. Berger, K.A. Bjorndal, L.W. Botsford, B.J. Bourque, R.H. Bradbury, R. Cooke, J. Erlandson, J.A. Estes, and others. 2001. Historical overfishing and the recent collapse of coastal ecosystems. Science 293:629-638.

James, M.K., P.R. Armsworth, L.B. Mason, and L. Bode. 2002. The structure of reef fish metapopulations: Modelling larval dispersal and retention patterns. Proceedings of the Royal Society of London, Series B 269: 2,079-2,086.

Jameson, S.C., M.H. Tupper, and J.M. Ridley. 2002. The three screen doors: Can marine "protected" areas be effective? Marine Pollution Bulletin 44:1,177-1,183.

Jones, G.P., R. Cole, and C.N. Battershill. 1993. Marine reserves: Do they work? Pp. 29-45 in The Ecology of Temperate Reefs: Proceedings of the Second International Temperate Reef Symposium, Auckland. NIWA Publications, Wellington. ISBN 0-478-08327-0.

Jones, G.P., M.I. McCormick, M. Srinivasan, and J.V. Eagle. 2004. Coral decline threatens fish biodiversity in marine reserves. Proceedings of the National Academy of Sciences of the United States of America 101:8,251-8,253.

Jones, G.P., M.J. Milicich, M.J. Emslie, and C. Lunow. 1999. Self-recruitment in a coral reef fish population. Nature 402:802-804.

Jones, G.P., P.L. Munday, and M.J. Caley. 2002. Rarity in coral reef fish communities. Pp. 81-101, in Coral Reef Fishes: Dynamics and diversity in a complex ecosystem. P.F. Sale, ed., Academic Press, San Diego.

Jones, G.P., S. Planes, and S.R. Thorrold. 2005. Coral reef fish larvae settle close to home. Current Biology $15: 1,314-1,318$.

Kaplan, D.M., and L.W. Botsford. 2005. Effects of variability in spacing of coastal marine reserves on fisheries yield and sustainability. Canadian Journal of Fisheries and Aquatic Sciences 62:905-912.

Kappel, C.V. 2005. Losing pieces of the puzzle: Threats to marine, estuarine and diadromous species. Frontiers in Ecology and Environment 3:275-282.

Kinlan, B.P., and S.D. Gaines. 2003. Propagule dispersal in marine and terrestrial environments: A community perspective. Ecology 84:2,007-2,020.

Kritzer, J.P. 2004. Effects of noncompliance on the success of alternative designs of marine protected area networks for conservation and fisheries management. Conservation Biology 18:1,021-1,031.

Kritzer, J.P., and P.F. Sale. 2004. Metapopulation ecology in the sea: From Levins' model to marine ecology and fisheries science. Fish and Fisheries 5:131-140

Laurel, B.J., and I.R. Bradbury. 2006. "Big" concerns with high latitude marine protected areas (MPAs) Trends in connectivity and MPA size. Canadian Journal of Fisheries and Aquatic Science 63: 2,603-2,607.

Levin, L.A. 2006. Recent progress in understanding larval dispersal: New directions and digressions. Integrative and Comparative Biology 46:282-297.

Little, L.R., A.D.M. Smith, A.D. McDonald, A.E. Punt, B.D. Mapstone, F. Pantus and C.R. Davies.
2005. Effects of size and fragmentation of marine reserves and fisher infringement on the catch and biomass of coral trout, Plectropomus leopardus, on the Great Barrier Reef, Australia. Fisheries Management and Ecology 12:177-188.

Lockwood, D.R., A. Hastings, Botsford, L.W. 2002. The effects of dispersal patterns on marine reserves: Does the tail wag the dog? Theoretical Population Biology 61:297-309.

Lomolino, M.V. 1994. An evaluation of alternative strategies for building networks of nature reserves. Biological Conservation 69:243-249.

Lotze, H.K., H.S. Lenihan, B.J. Bourque, R.H. Bradbury, R.G. Cooke, M.C. Kay, S.M. Kidwell, M.X. Kirby, C.H. Peterson, and J.B.C. Jackson. 2006. Depletion, degradation, and recovery potential of estuaries and coastal seas. Science 312:1,806-1,809.

Margules, C., A.J. Higgs, and R.W. Rafe. 1982. Modern biogeographic theory: Are there any lessons for nature reserve design? Biological Conservation 24:115-128.

McClanahan, T.R. 2002. The near future of coral reefs. Environmental Conservation 29:460-483.

McNeill, S.E., and Fairweather, P.G. 1993. Single large or several small marine reserves? An experimental approach with seagrass fauna. Journal of Biogeography 20:429-440.

Micheli, F., B.S. Halpern, L.W. Botsford, and R.R. Warner. 2004. Trajectories and correlates of community change in no-take marine reserves. Ecological Applications 14:1,709-1,723.

Mora, C., S.Andréfouët, M.J. Costello, C. Kranenburg, A. Rollo, J. Veron, K.J. Gaston, and R.A. Myers. 2006. Coral reefs and the global network of marine protected areas. Science 312:1,750-1,751.

Munday, P.L., G.P. Jones, M. Sheaves, A.J. Williams, and G. Goby. 2007. Vulnerability of fishes of the Great Barrier Reef to climate change. Pp. 357-391 in Climate Change and the Great Barrier Reef. P. Marshall and J. Johnson, eds, Great Barrier Reef Marine Park Authority.

Nardi, K., G.P. Jones, M.J. Moran, and Y.W. Cheng. 2004. Contrasting effects of marine protected areas on the abundances of two exploited reef fishes at the sub-tropical Houtman Abrolhos Islands, Western Australia. Environmental Conservation 31:160-169.

Orth, R.J., T.J.B. Carruthers, W.C. Dennison, C.M. Duarte, J.W. Fourqurean, W. James, H.K. Heck Jr, A.R. Hughes, G.A. Kendrick, W.J. Kenworthy, and others. 2006. A global crisis for seagrass ecosystems. Bioscience 56:987-996.

Palumbi, S.R. 2004. Marine reserves and ocean neighborhoods: The spatial scale of marine populations and their management. Annual Review of Environment and Resources 29:31-68.

Palumbi, S.R., S.D. Gaines, H. Leslie, and R.R. Warner. 2003. New wave: High-tech tools to help marine reserve research. Frontiers in Ecology and Environment 1:73-79. 
Perez-Ruzafa A., M. Gonzalez-Wanguemert, P. Lenfant, C. Marcos, and J.A. Garcia-Charton. 2006. Effects of fishing protection on the genetic structure of fish populations. Biological Conservation 129:244-255.

Powles, H., M.J. Bradford, R.G. Bradford, W.G. Doubleday, S. Innes, and C.D. Levings. 2000. Assessing and protecting endangered marine species. ICES Journal of Marine Sciences 57:669-676.

Pressey, R.L., C.J. Humphries, C.R. Margules, R.I. Vane-Wright, and P.H. Williams. 1993. Beyond opportunism: Key principles for systematic reserve selection. Trends in Ecology and Evolution 8:124-128.

Purcell, J.F.H., R.K. Cowen, C.R. Hughes, and D.A. Williams. 2006. Weak genetic structure indicates strong dispersal limits: A tale of two coral reef fish. Proceedings of the Royal Society, Series $B$ 273:1,483-1,490.

Reynolds, J.D., N.K. Dulvy, N.B. Goodwin, and J.A. Hutchings. 2005. Biology of extinction risk in marine fishes. Proceeding of the Royal Society, Series B 272:2,337-2,344.

Roberts, C.M. 1997. Connectivity and management of Caribbean coral reefs. Science 278:1,454-1,457.

Roberts, C.M., S. Andelman, G. Branch, R.H. Bustamante, J.C. Castilla, J. Dugan, B.S. Halpern, K.D. Lafferty, H. Leslie, J. Lubchenco, and others. 2003. Ecological criteria for evaluating candidate sites for marine reserves. Ecological Applications 13:S199-214.

Roberts, C.M., and J.P. Hawkins. 1997. How small can a marine reserve be and still be effective? Coral Reefs 16:150.

Roberts, C.M., and J.P. Hawkins. 1999. Extinction risk in the sea. Trends in Ecology and Evolution 14:241-246

Roberts, C.M., C.J. McClean, J.E.N. Veron, J.P. Hawkins, G.R. Allen, D.E. McAllister, C.G. Mittermeier, F.W. Schueler, M. Spalding, F. Wells, and others. 2002. Marine biodiversity hotspots and conservation priorities for tropical reefs. Science 295:1,280-1,284.

Roberts, C.M., and N.V.C. Polunin. 1991. Are marine reserves effective in management of reef fisheries? Reviews in Fish Biology and Fisheries 1:65-91.

Roberts, C.M., J.D. Reynolds, I.M. Côté, and J.P. Hawkins. 2006. Redesigning coral reef conservation. Pp. 515-537 in Coral Reef Conservation, I.M. Cote and J.D. Reynolds, eds, Cambridge University Press.

Rogers, C.S., and J. Beets. 2001. Degradation of marine ecosystems and decline of fishery resources in marine protected areas in the US Virgin Islands. Environmental Conservation 28:312-322.

Sadovy, Y. 1993. The Nassau grouper: Endangered or just unlucky? Reef Encounter 13:10-12.

Sala, E., O. Aburto-Oropeza, G. Paredes, I. Parra, J.C. Barrera, and P.K. Dayton. 2002. A general model for designing networks of marine reserves. Science 298:1,991-1,993.
Sala, E., E. Ballesteros, and R.M. Starr. 2001. Rapid decline of Nassau grouper spawning aggregations in Belize: Fishery management and conservation needs. Fisheries 26:23-30.

Sale, P.F., R.K. Cowen, B.S. Danilowicz, G.P. Jones, J.P. Kritzer, K.C. Lindeman, S. Planes, N.V.C. Polunin, G.R. Russ, Y.J. Sadovy, and R.S. Steneck. 2005. Critical science gaps impede use of no-take fishery reserves. Trends in Ecology and Evolution 20:74-80.

Salm, R.V., T. Done, and E. McLeod. 2006. Marine protected area planning in a changing climate. Pp. 207-221 in Coral Reefs and Climate Change: Science and Management. Coastal and Estuarine Studies 61, American Geophysical Union.

Shanks, A.L., B.A. Grantham, and M.H. Carr. 2003. Propagule dispersal distance and the size and spacing of marine reserves. Ecological Applications 13:S159-S169.

Simberloff, D. 1988. The contribution of population and community biology to conservation science. Annual Review of Ecology and Systematics 19:473-511.

Steneck, R.S., M.H. Graham, B.J. Bourque, D. Corbett, J.M. Erlandson, J.A. Estes, and M.J. Tegner. 2002. Kelp forest ecosystems: Biodiversity, stability, resilience and future. Environmental Conservation 29:436-459.

Stockhausen, W.T., and R.N. Lipcius. 2001. Single large or several small marine reserves for the Caribbean spiny lobster? Marine and Freshwater Research 52:1,605-1,614.

Swearer, S.E., J.E. Caselle, D.W. Lea, and R.R. Warner. 1999. Larval retention and recruitment in an island population of a coral-reef fish. Nature 402:799-802.

Thorrold, S.R., R.S. Burton, G.P. Jones, M.E. Hellberg, S.E. Swearer, J.E. Niegel, S.G. Morgan, and R.R. Warner. 2002. Quantifying larval retention and connectivity in marine populations with artificial and natural markers: Can we do it right? Bulletin of Marine Science 70:291-308.

Turpie, J.K., L.E. Beckley, and S.M. Katua. 2000 Biogeography and the selection of priority areas for conservation of South African coastal fishes. Biological Conservation 92:59-72.

Vincent, A.C.J., and Y. Sadovy. 1998. Reproductive ecology in the conservation management of fishes. Pp. 209-245 in Behavioural Ecology and Conservation Biology, T. Caro, ed., Oxford University Press, New York.

Worthen, W.B. 1996. Community composition and nested-subset analyses: Basic descriptors for community ecology. Oikos 76:417-426. 